\title{
Trabalho Digno, Satisfação Com o Trabalho e com a Vida em Administradores
}

\author{
Renan Lopes Cipriani ${ }^{1}$, Tânia Ferraro², Cecília Leão Oderich ${ }^{3}$
}

\footnotetext{
${ }^{1}$ http://orcid.org/0000-0001-8549-2603 / Universidade Estadual do Oeste do Paraná, Brasil

${ }^{2}$ http://orcid.org/0000-0002-8293-1946 / Universidade Portucalense, Portugal; Faculdade de Psicologia e Ciências da Educação, Universidade de Coimbra, Portugal

${ }^{3}$ http://orcid.org/0000-0002-1776-7019 / Universidade Estadual do Oeste do Paraná, Brasil
}

\section{Resumo}

O presente estudo objetivou avaliar interações entre a percepção do trabalho digno (TD) e a satisfação com o trabalho e com a vida, em uma amostra de administradores brasileiros $(N=292)$. Para isto, foram aplicados três instrumentos: o Questionário de Trabalho Digno, o Questionário de Satisfação com o Trabalho e a Escala de Satisfação com a Vida. Os resultados encontrados foram três correlações canônicas interpretáveis: a primeira mostra a associação de todas as dimensões do TD com todas as dimensões da satisfação com o trabalho e com a vida; a segunda, evidencia a interação entre a remuneração significativa para o exercício da cidadania e a satisfação com a vida; e a terceira, destaca a associação entre a saúde e segurança com a satisfação com o ambiente físico do trabalho. Os resultados sugerem a relevância do TD na promoção da satisfação com o trabalho e com a vida.

Palavras-chave: trabalho digno, satisfação com o trabalho e com a vida, correlações canônicas.

\section{Decent Work, and Satisfaction with Work and Life in Managers}

Abstract

The present study aimed to explore interactions between decent work (DW) perception and satisfaction with work and life, in a sample of Brazilian managers $(N=292)$. For this, three instruments were applied: The Decent Work Questionnaire, the Work Satisfaction questionnaire and the Satisfaction With Life Scale. The results found were three interpretable canonical correlations: the first shows the association of all DW dimensions with all dimensions of satisfaction with work and life; the second shows the interaction between meaningful remuneration for the exercise of citizenship and satisfaction with life; and the third, highlights the association between health and safety with satisfaction with the physical work environment. The results suggest the relevance of DW in promoting satisfaction with work and life.

Keywords: decent work, job and life satisfaction, canonical correlations.

\section{Trabajo Decente, Satisfacción con el Trabajo y con la Vida en Administradores}

\section{Resumen}

El presente estudio tuvo como objetivo evaluar las interacciones entre la percepción del trabajo decente (TD) y la satisfacción con el trabajo y con la vida, en una muestra de administradores brasileños $(N=292)$. Para eso, se aplicaron tres instrumentos: el Cuestionario de Trabajo Decente, el Cuestionario de Satisfacción Laboral y la Escala de Satisfacción con la Vida. Los resultados encontrados fueron tres correlaciones canónicas interpretables: la primera presenta la asociación de todas las dimensiones del TD con todas las dimensiones de satisfacción con el trabajo y con la vida; la segunda muestra la interacción entre la remuneración significativa para el ejercicio de la ciudadanía y la satisfacción con la vida; y la tercera, destaca la asociación entre salud y seguridad con la satisfacción con el ambiente físico de trabajo. Los resultados sugieren la importancia del TD en la promoción de la satisfacción con el trabajo y la vida.

Palabras clave: trabajo decente, satisfacción laboral y con la vida, correlaciones canónica. 
$\mathrm{Na}$ área da Administração, o estudo sistemático do trabalho, enquanto elemento fundamental de coesão social e engrenagem essencial das organizações, tem sido objeto de estudo científico desde a chamada Teoria Clássica da Administração, a partir das obras de Frederick Taylor nos Estados Unidos e de Henri Fayol, na França (Sá, 2016). Fayol sistematizou as ideias que contribuíram para a compreensão da estrutura organizacional, com foco nas funções e desempenho dos gestores. Segundo Sá (2016), Fayol ainda definiu a gestão como uma ciência responsável por visualizar o futuro, traçar planos de ação, dar direção e orientação à equipe de trabalho, além de harmonizar esforços e acompanhar o cumprimento das ordens, bem como a concretização dos objetivos. Para tanto, o gestor deveria ser capaz, principalmente, de formular planos, organizar a empresa e equipamentos e lidar com pessoas (Sá, 2016). Estas funções, atribuídas por Fayol ao profissional da gestão, mantém-se na essência da profissão do administrador até a atualidade.

Neste desenvolvimento histórico, observa-se que foi Mayo o responsável por trazer à tona a preocupação com o fator humano nas organizações (Sá, 2016). Através dos estudos de Hawthorne, seminais da Teoria das Relações Humanas, constatou-se a importância do fator humano, das interações em grupos informais, além da necessidade de humanização das organizações. Ressaltar a necessidade de criar formas de tratamento mais humanas, e adotar políticas administrativas a partir das quais as pessoas sintam-se respeitadas no ambiente de trabalho podem ser consideradas as maiores contribuições da Teoria das Relações Humanas. Segundo Sá (2016), estudar o desenvolvimento da gestão é investigar a "história da evolução de um conjunto de concepções da natureza do homem, trabalho e funcionamento das organizações" (p. 35). Desde sempre e ainda mais na atualidade, os gestores têm um papel fundamental como responsáveis por orquestrar os recursos organizacionais e levar as organizações aos seus objetivos.

Após o término da $1^{\text {a }}$ Guerra Mundial, a valorização do trabalho como elemento fundamental da promoção da coesão social ganhou ainda mais destaque através do Tratado de Versalhes (de 1919; Ferraro, dos Santos, Pais, \& Mónico, 2016). Por tratar-se de um tema de suma relevância ao contexto social, à promoção da justiça social e, consequentemente, para a manutenção da paz mundial, criou-se uma agência específica para tratativas relacionadas ao trabalho, denominada Organização Internacional do Trabalho (OIT), a fim de responder às questões internacionais do trabalho (Ferraro et al., 2016).

O conceito de Trabalho Digno (TD) surge como um desdobramento dos objetivos da própria OIT. É um conceito que passou por um processo de gestação por todo o século XX, desenvolvido de modo mais dinâmico a partir de 1999. Ferraro et al. (2016) elencaram os marcos históricos deste desenvolvimento e ressaltaram que em 1999, através das palavras de Juan Somavía (Diretor-Geral da OIT), o conceito ganhou forma, apresentado como "o ponto de convergência de quatro objetivos estratégicos: a promoção dos direitos fundamentais no trabalho, o emprego, a proteção social e o diálogo social" (International Labour Organization ILO, 1999, p. 3); e a criação de oportunidades (para mulheres e homens) para conquistarem trabalhos dignos e produtivos "em condições de liberdade, equidade, segurança e dignidade humana” (ILO, 1999, p. 3). Neste sentido, significa o respeito aos direitos humanos no trabalho, o que, na prática, traduz-se em assegurar às pessoas a participação nas decisões relevantes quanto ao próprio trabalho, o reconhecimento devido pelo trabalho realizado, oportunidades de desenvolvimento pessoal e profissional, renda adequada que permita o exercício da cidadania e garanta o bem-estar do trabalho e daqueles que dele dependem, justiça e equidade de gênero no trabalho. Em uma perspectiva macrossocial, o TD se faz essencial na promoção de esforços voltados à redução da pobreza e na garantia de consecução de um desenvolvimento sustentável, equitativo e inclusivo (OIT, 2009).

$\mathrm{O}$ avanço da globalização trouxe consequências positivas e negativas por todo o mundo: gerou oportunidades econômicas, mas, ao mesmo tempo, tem contribuído para a desigualdade social (OIT, 2001). Assim, o conceito de TD proposto no âmbito da OIT é um esforço institucional e internacional para combater a degradação do mercado de trabalho (Ferraro et al., 2016). Ferraro, Pais, e dos Santos (2015) afirmam que o TD se trata de uma responsabilidade comum e partilhada entre líderes políticos, empresários, trabalhadores e demais agentes econômicos e sociais. É necessário o envolvimento de todos para que os objetivos sejam progressivamente atingidos.

Relativamente a importância do trabalho na vida das pessoas, Dejours (2017) refere que a centralidade do trabalho tem cinco dimensões: a centralidade do trabalho quanto à saúde mental; quanto às relações sociais; quanto às transformações na urbe; à economia e à teoria do conhecimento (ou epistemologia). Estas 5 facetas compõe a tese da "centralidade do trabalho" para as pessoas e ajudam a compreender a psicodinâmica do trabalho. Esta, por sua vez, procura explicar não apenas o sofrimento e as patologias mentais que podem advir do trabalho, mas também o modo como o trabalho pode ser uma fonte de prazer e ter um papel importante na construção da saúde das pessoas. Para Dejours (2017), a psicodinâmica do trabalho tem sua vertente teórica mas também prática. Esta intervenção prática pode se dar tanto (a) nos consultórios, onde se desenvolve a perspectiva clínica e é feito o atendimento daqueles que sofrem consequências danosas do trabalho; e, (b) nas empresas, onde é possível procurar transformar a organização do trabalho como um recurso de realização pessoal. No presente estudo, nos concentramos nesta segunda arena. As organizações como locais onde são possíveis as transformações da organização do trabalho para promoção da saúde das pessoas.

No presente estudo, pretendeu-se avaliar o papel do trabalho digno como promotor da satisfação com o trabalho e com a vida. Neste sentido, pretendemos verificar sua função como antecedente destes dois tipos de satisfação. Por aproximação ao tema, encontramos o estudo empírico de Koh e Boo (2001) com Administradores, o qual mostra a conexão entre a ética organizacional (representada pelas medidas do suporte da gestão de topo para comportamentos éticos, clima organizacional ético, e a relação entre o comportamento ético e o sucesso na carreira) e a satisfação com o trabalho. Os seus resultados indicam que os líderes organizacionais podem influenciar favoravelmente os resultados organizacionais ao engajarem-se, oferecerem suporte e recompensarem o comportamento ético. Eles fundamentaram seu estudo: na literatura dos "practitioners" (profissionais que atuam no mercado de trabalho na área da Administração); na teoria da justiça organizacional e na teoria da dissonância cognitiva. Este conjunto foi o alicerce da interpretação do estudo e apresenta evidências da associação entre ética (seja um ambiente ético ou relações éticas no trabalho) e a satisfação com o trabalho. Lau, Wong, e Eggleton (2008) também mostraram a relação entre a percepção de justiça nos procedimentos relativos à avaliação de desempenho e a satisfação com o trabalho em uma amostra de administradores. Garcia-Izquierdo, Moscoso, e Ramos-Villagrasa (2012) verificaram a relação entre as reações a percepção de justiça em métodos e sistemas de promoção (justiça procedimental) e a satisfação com o trabalho. Eles concluíram que a justiça organizacional é fortemente relacionada com a satisfação com o trabalho.

Khaleque e Choudhury (1984) consideravam que a satisfação com o trabalho (ou a insatisfação) são funções da interação percebida entre o que o indivíduo espera e o que obtém do seu traba- 
lho e quanta importância ou valor atribui a isto. Bergmann (1981) também afirmou que a satisfação com o trabalho está comumente relacionada às características do trabalho. Ele destacou que "para gerar satisfação, o trabalho não deve ser apenas desafiador, mas também significativo e pessoalmente interessante" (p. 276). Droussiotis e Austin (2007) referem que os trabalhadores em geral estão cada vez mais interessados em trabalhos que sejam significativos. É possível afirmar que a relação entre o trabalho digno e a satisfação com o trabalho é aparentemente intuitiva visto que faz todo o sentido esperar que ambientes profissionais nos quais os trabalhadores percebam o seu trabalho como digno, seja também um ambiente favorável a avaliação deste trabalho como satisfatório.

O estudo da satisfação com o trabalho é um tema já há muito pesquisado principalmente no que se refere: (a) a sua controversa relação com a performance no trabalho e o quanto pode contribuir para a eficácia organizacional (Droussiotis \& Austin, 2007; Petty, McGee, \& Cavender, 1984; Ng, Sorensen, \& Yim, 2009); ou ainda (b) sua interação com a intenção de mudar de emprego (Droussiotis \& Austin, 2007; Ghiselli, La Lopa, \& Bai, 2001). Quanto a performance (a): as correntes teóricas variam: algumas defendem que a satisfação com o trabalho aumenta o desempenho, estas têm raízes na Escola das Relações Humanas a partir dos estudos de Hawthorne. Outras teorias ressaltam uma interação inversa: na qual o bom desempenho pode levar a recompensas e estas à satisfação com o trabalho (Petty et al., 1984). Há ainda outras teorias que consideram que a satisfação com o trabalho e a performance influenciam-se mutuamente (Judge, Thoresen, Bono, \& Patton, 2001). Estes autores referem pelo menos 7 modelos diferentes para o modo como estes conceitos poderiam se relacionar e criar modelos conceituais diferentes. Quanto à intenção de deixar o emprego atual (b): Ghiselli, La Lopa, e Bai (2001) referem que a compreensão da satisfação com o trabalho é um aspecto fundamental da intenção de deixar o emprego atual. Apesar da relevância de ambos os temas, nem o conceito de performance, nem a 'intenção em deixar o emprego' foram medidos no presente estudo. A controvérsia em torno destes temas foi mencionada devido a relevância destes temas para a Administração, e pelo grande volume de literatura previamente produzido sobre esses assuntos, o que fortalece a importância de uma melhor compreensão a respeito da satisfação no trabalho e seus antecedentes, como no presente estudo.

Em um estudo realizado por Qu e Zhao (2012) com administradores da área de Vendas, ficou destacada a importância do equilíbrio trabalho-família para a satisfação com o trabalho. Estes autores concluem que políticas de Recursos Humanos que sejam amigas das famílias, ou seja, que incentivem este equilíbrio podem contribuir para aumentar os resultados da organização. Pradhan, Dash e Jena (2019) enfatizam que a satisfação no trabalho é fundamental não somente para o desenvolvimento das organizações, mas também aos aspectos profissionais e pessoais dos trabalhadores. Desenvolver a satisfação dos trabalhadores é, portanto, apontada como vantagem competitiva ao proporcionar melhores resultados no alcance dos objetivos organizacionais.

Segundo Carlotto e Câmara (2008), "a satisfação no trabalho é definida como um conjunto de sentimentos favoráveis ou desfavoráveis com os quais os trabalhadores percebem seu trabalho" (p. 203). Pode ser considerada como uma função de relação percebida entre o que um indivíduo quer de seu trabalho e a percepção do que ele obtém (Locke, 1976; Khaleque \& Choudhury, 1984). Para Locke (1976) considera-se como um estado emocional agradável resultante de um processo avaliativo que a pessoa faz de seu trabalho, resultado da percepção do indivíduo sobre como este satisfaz ou permite a satisfação de seus valores importantes no trabalho. Ainda segundo Locke (1976), a satisfação com o trabalho pode ser descrita como o atendimento pleno das necessidades. $\mathrm{O}$ conceito passou por diferentes revisões e reperspectivações, visto então como uma variável atitudinal. Algumas abordagens teóricas o veem como um construto mais afetivo e, na atualidade, prepondera a sua compreensão a partir dos processos cognitivos.

Spector (1997) apresenta uma noção bastante abrangente de que a satisfação com o trabalho representa o grau que uma pessoa aprecia ou julga (no sentido avaliativo e, portanto, cognitivamente) o seu próprio trabalho, ou ainda, como a pessoa sente sobre o seu trabalho e seus diferentes aspectos ainda segundo uma avaliação cognitiva.

A satisfação no trabalho pode ser estudada como uma variável multidimensional, pois pode agrupar uma apreciação global ou de conjunto, ou ainda a aspectos específicos do mesmo (Carlotto \& Câmara, 2008; Cook, Hepworth, Wall, e Warr, 1989; Hora, Ribas, \& Souza, 2018). Rueda (2015) explica esta multidimensionalidade do construto ao considerar a diversidade de componentes existentes no que tange ao estudo da satisfação no trabalho.

Rain, Lane, \& Steiner (1991) também referiam a relação entre a satisfação com o trabalho e com a vida como uma interação com um apelo intuitivo. Sendo o trabalho uma parte essencial da vida de muitas pessoas, a satisfação no trabalho, muitas vezes, pode transcender os limites do trabalho. Locke (1976) sugere que a satisfação no trabalho exerce influência na satisfação com a vida através da generalização das emoções do trabalho para a vida fora do trabalho e de atitudes decorrentes, que podem exercer efeito, especificamente, nas relações sócio-familiares. A satisfação global no trabalho é, portanto, um dos principais componentes da satisfação geral com a vida (Zalewska, 1999). Kantak, Futrell, e Sager (1992) defendiam que nós, humanos, não conseguimos separar totalmente uma parte da vida das outras partes, por exemplo, quando temos um mal dia no trabalho isto pode gerar problemas em casa e, talvez, no caso dos administradores, o que ainda os preocupe mais é quando problemas em casa podem causar dificuldades no trabalho. Judge et al. (2002) referem que existiriam, pelo menos, 3 formas de interação entre a satisfação com o trabalho e a satisfação com a vida: o transbordamento (quando aquilo que acontece no trabalho afeta a vida familiar e vice-versa, como no exemplo anterior); a segmentação (quando o trabalhador procura separar o trabalho da vida pessoal, como "setores" completamente afastados); e, a compensação (quando uma pessoa tenta compensar a insatisfação no trabalho, por exemplo, ao buscar realização e felicidade em outros setores da vida pessoal como forma de compensação, ou vice-versa). Independentemente da forma de interação entre esses setores da vida, Judge et al. (2002) afirmam que a interação entre a satisfação com o trabalho e a satisfação com a vida é de reciprocidade: afetam-se mutuamente.

Entre as satisfações específicas que podem ser estudadas, a satisfação com a remuneração e os benefícios sociais no trabalho também pode afetar a satisfação com a vida. A remuneração recebida pelo trabalhador, como defendem Vieira, Appio \& Slongo (2007), "pode interferir na satisfação e auto-estima do trabalhador” (p. 5), pois a compensação recebida pelo trabalho realizado é muitas vezes utilizada para realizar diversos objetivos da vida do trabalhador.

A satisfação com a vida representa uma avaliação ou julgamento cognitivo global da satisfação de alguém com sua vida como um todo (Pavot \& Diener, 2008). Anteriormente, Diener (1984) já havia definido a satisfação com a vida como uma avaliação cognitiva de sua vida em geral, ou seja, um julgamento avaliativo (uma vez mais destaca-se o aspecto cognitivo, também referido em Diener, Emmons, Larsen, \& Griffin, 1985).

Beutell e Schneer (2014) afirmam que a saúde mental e os temas relativos ao equilíbrio entre trabalho e família são os mais importantes preditores tanto da satisfação com o trabalho quanto 
com a satisfação com a vida. Portanto, um trabalho que seja percebido como digno, que promova e proteja a saúde mental das pessoas, e que respeite o equilíbrio de tempo e carga de trabalho que favoreçam esta interação entre o trabalho e a família deve favorecer a satisfação com o trabalho e a vida. Ainda segundo Pavot e Diener (2008):

De uma perspectiva mais abrangente, há ampla evidência de que altos níveis de satisfação com a vida e afeto positivo (ou seja, felicidade) estão relacionados a uma ampla gama de resultados de vida importantes, como ambos saúde física e mental e relações sociais. (p. 141).

Ao considerar-se o papel de destaque das organizações na sociedade, fica ainda mais evidente a relevância dos administradores, requisitados nos mais diversos setores. No Brasil, segundo o último levantamento nacional divulgado pelo Conselho Federal de Administração (CFA, 2015), havia mais de 340 mil administradores com registro profissional, perfilando uma maioria de homens (mas com expressivo crescimento de mulheres), egressos de universidades particulares, com atuação em empresas privadas e ocupação de cargos de gerente e de analista. No que diz respeito ao trabalho, quando questionados sobre as atitudes mais relevantes, destacou-se o comportamento ético. Cabe ressaltar que mais de $73 \%$ realizaram especialização, em diferentes áreas, com destaque para conhecimentos específicos predominantes "para a área estratégica da empresa e para administração de pessoas, de finanças e orçamento" (p. 31). Além da diversidade de especialidades, muitos optam por seguir uma carreira empreendedora, desenvolvendo seus próprios negócios ou na condição de profissionais autônomos.

Assim, ao se considerar a relevância destes profissionais na contemporaneidade, a presente pesquisa procurou compreender o papel do TD para a promoção da Satisfação com o Trabalho e com a Vida em uma amostra de Administradores no Brasil, a partir das seguintes questões norteadoras ou "rationales" a serem verificados: (1) Rationale 1: elevada percepção de um trabalho digno está relacionada com elevada satisfação com o trabalho; e Rationale 2: elevada percepção de um trabalho digno está relacionada com elevada satisfação com a vida.

\section{Método}

\section{Participantes}

Inicialmente, a amostra foi composta por 313 participantes. Entretanto, a análise dos casos extremos (univariados e multivariados, Meyers, Gamst, \& Guarino, 2017) nos obrigou a retirar 21 casos e a amostra passou a ser composta por 292 administradores(as) que atuam profissionalmente em sua área de formação, com diferentes especialidades. Quanto ao gênero, a amostra encontra-se relativamente balanceada, composta por $51,4 \%$ de mulheres. Temos uma concentração de participantes na faixa entre os 36 e 50 anos, seguida da faixa etária mais jovem entre os 21 e 35 anos, com a idade média da amostra em torno de 40 anos ( $S D=$ 11,19), o participante mais jovem tem 22 anos e o mais velho 74 anos. Quanto à escolaridade, identifica-se uma concentração de profissionais com mestrado e/ou pós-graduação (45,9\%), como pode ser observado na Tabela 1 (abaixo). Relativamente, ao estado civil, a maior parte da nossa amostra é composta por participantes casado (66,1\%) seguidos pelos participantes solteiros (26\%), que somados totalizam $92,1 \%$ da amostra. Quanto ao tempo no atual trabalho/cargo, ressalta-se ainda uma concentração de participantes com mais de 6 meses até 10 anos na função que desempenham
Tabela 1

Características demográficas da amostra $(\mathrm{N}=292)$

\begin{tabular}{|c|c|c|}
\hline Características & $n$ & $\%$ \\
\hline \multicolumn{3}{|l|}{ Gênero } \\
\hline Homens & 142 & 48,6 \\
\hline Mulheres & 150 & 51,4 \\
\hline \multicolumn{3}{|l|}{ Idade (em anos) } \\
\hline De 21 até 35 & 115 & 39,4 \\
\hline De 36 até 50 & 125 & 41,8 \\
\hline De 51 até 65 & 47 & 16,1 \\
\hline De 66 até 80 & 8 & 2,7 \\
\hline \multicolumn{3}{|l|}{ Escolaridade } \\
\hline Graduação completa & 94 & 32,2 \\
\hline Mestrado e/ou pós-graduação (ou equivalente) & 134 & 45,9 \\
\hline Doutorado ou Pós-Doutorado & 64 & 21,9 \\
\hline \multicolumn{3}{|l|}{ Estado civil } \\
\hline Solteiro & 76 & 26,0 \\
\hline Casado(a) / União Estável & 193 & 66,1 \\
\hline Separado(a) / Divorciado(a) & 20 & 6,9 \\
\hline Viúvo(a) & 3 & 1,0 \\
\hline \multicolumn{3}{|l|}{$\begin{array}{l}\text { Tempo no atual trabalho/cargo (atual contexto de } \\
\text { trabalho; em anos) }\end{array}$} \\
\hline Mais de 6 meses até 10 anos & 213 & 73,0 \\
\hline De 11 a 20 anos & 54 & 18,5 \\
\hline De 21 a 30 anos & 16 & 5,5 \\
\hline De 31 a 40 anos & 8 & 2,7 \\
\hline Mais de 40 anos & 1 & 0,3 \\
\hline
\end{tabular}

(ou seja, no atual contexto de trabalho).

\section{Instrumentos}

Quanto aos instrumentos de coleta de dados, foram utilizados três instrumentos psicométricos: O Questionário de Trabalho Digno (QTD), o Questionário de Satisfação com o Trabalho (QST - S20/23) e a Escala de Satisfação com a vida (ESV).

Questionário de Trabalho Digno (QTD). O Questionário de Trabalho Digno (QTD) foi desenvolvido por Ferraro et al. (2018) como um instrumento de medida da percepção dos trabalhadores sobre seu próprio trabalho no que se refere às diversas facetas do trabalho digno. Ele é composto por 31 itens, dispostos em 7 dimensões: a primeira delas 'Princípios e valores fundamentais no trabalho' representa os itens relativos à justiça, dignidade, liberdade e aceitação (sem discriminação) no local de trabalho, o tratamento justo, clareza de normas, entre outros aspectos (TD1, exemplo de um item desta dimensão, "sou livre para pensar e expressar o que penso sobre o meu trabalho"); a segunda dimensão chamada 'Tempo e carga de trabalho adequadas' agrupa os itens que referem-se à adequada gestão do tempo, uma boa distribuição entre o tempo dedicado ao trabalho e à família e/ou vida pessoal (TD2, exemplo, “considero adequada a quantidade média de horas que trabalho por dia"); 'Trabalho realizante e produtivo' é a terceira dimensão e reúne os itens associados ao desenvolvimento pessoal e profissional através do trabalho, a realização pessoal e profissional que o trabalho traz, a contribuição que o trabalho realizado faz para o futuro das novas gerações, e a criação de valor para diversos stakeholders (TD3, exemplo, "considero digno o trabalho que realizo"); a quarta dimensão é a 'Remuneração significativa para o exercício da cidadania' e representa os itens relativos a uma vida que pode ser vivida com dignidade e autonomia em função dos ganhos que são recebidos do trabalho; ganhos que permitem uma vida digna e autónoma e oferecer bem-estar para si 
e para aqueles que do trabalhador dependem (TD4, exemplo: "o que ganho financeiramente com o meu trabalho é justo"); a quinta dimensão chama-se 'Proteção social' por agrupar os itens que traduzem a percepção de estar ou sentir-se protegido em caso de perda do emprego ou em caso de doença, também refere-se à proteção que se estende à família do trabalhador e representa, ainda, as expectativas que o trabalhador tem quanto a forma como a sociedade retribui ou reconhece os esforços que ele faz no trabalho [TD5, exemplo: "Sinto que estou protegido(a) caso fique sem trabalho (subsídios sociais, programas sociais, entre outros)"]; a sexta dimensão chama-se 'Oportunidades' porque reúne os itens relativos aos temas da empregabilidade, empreendedorismo e as possibilidade de construção de um futuro melhor através do trabalho, expressa a expectativa de receber promoções, melhores salários ou benefícios, além de oportunidade de desenvolvimento pessoal e profissional através de formações (TD6, exemplo, "atualmente, penso que há oportunidades de trabalho para um profissional como eu'); e, a sétima dimensão 'Saúde e segurança' expressa a percepção que o trabalhador possa ter quanto à proteção dos riscos à sua saúde física, a disponibilidade que este identifica de tudo o que é necessário para manter a sua integridade física e segurança no local de trabalho, condições ambientais de trabalho saudáveis e seguras (TD7, exemplo, "disponho de tudo o que preciso para manter a minha integridade física no meu trabalho"). Cada item é respondido em uma escala Likert de 5 pontos, que varia entre $1=$ "não concordo nada" e $5=$ "concordo completamente". No estudo original, o alfa de Cronbach do TD Global foi de 0,93, e os fatores variaram de 0,72 a 0,93 no Brasil e de 0,76 a 0,92 em Portugal com um alfa de Cronbach de 0,92 de TD Global (Ferraro et al., 2018). O Alfa de Cronbach do TD Global no estudo atual foi de 0,95. O alfa de Cronbach para as demais dimensões do TD encontram-se na Tabela 2 (mais adiante), e variaram entre 0,74 e 0,94 .

Questionário de Satisfação com o Trabalho (QST S20/23). O Questionário de Satisfação com o Trabalho (QST-S20/23) foi desenvolvido por Meliá e Peiró (1989), na Espanha, e apresenta cinco fatores. Para o presente estudo, utilizou-se a versão adaptada e validada no Brasil por Carlotto e Câmara (2008), que apresenta três fatores. Este instrumento tem por objetivo medir o grau de satisfação proporcionado pelo trabalho, em uma escala Likert de 5 pontos que varia de 1 (= totalmente insatisfeito) a 5 (= totalmente satisfeito). O instrumento é composto por 23 itens, agrupados em 3 fatores: Satisfação com as relações hierárquicas (denominado pelas autoras SRH), com 11 itens (exemplo de um item: "Você está [ ] com o apoio recebido das instâncias superiores"); Satisfação com o ambiente físico de trabalho (SAFT), com 5 itens (ex.: "Você está [ ] com a iluminação de seu local de trabalho"); e Satisfação intrínseca no trabalho (SIT), com 4 itens (ex.: "Você está [ ] com as oportunidades que o trabalho lhe oferece de fazer coisas de que gosta"). No presente estudo também foram encontradas as três dimensões referidas por Carlotto e Câmara (2008), entretanto, realizamos uma nova Análise Fatorial Exploratória (AFE), apenas para confirmar o comportamento desta escala em uma nova amostra (os dados dessa AFE podem ser consultados através de solicitação aos autores), e encontramos ligeiras diferenças relatadas na seção dos 'resultados'. Devido a estas diferenças, a dimensão chamada anteriormente de SRH foi denominada Satisfação com as relações hierárquicas (QST1); Satisfação intrínseca no trabalho (QST2); e, Satisfação com o Ambiente Físico (QST3). Os Alfas de Cronbach encontrados para a Satisfação com o Trabalho Global e suas dimensões estão apresentados na Tabela 2 (mais adiante).

Escala de Satisfação com a Vida (ESV). A Escala de Satisfação com a vida é um instrumento elaborado por Diener et al. (1985), que objetiva avaliar o quão satisfeitas as pessoas encon- tram-se com suas vidas baseadas no julgamento global que fazem sobre a própria vida. Para o estudo atual, utilizou-se a versão brasileira adaptada e validada por Gouveia, Milfont, Fonseca, e Coelho (2009). O instrumento compõe-se de 5 itens que se agrupam de forma unidimensional (exemplo: "na maioria dos aspectos, minha vida é próxima ao meu ideal”) e oferece como opção de resposta uma escala Likert de 7 pontos que varia de 1 (= discordo totalmente) a 7 (= concordo totalmente). O Alfa de Cronbach para a Satisfação com a Vida pode ser consultado na Tabela 2 (mais adiante).

\section{Procedimentos de Coleta de Dados e Cuidados Éticos}

A composição da amostra foi planejada para acessar a profissionais da Administração de diversas especialidades com o objetivo de, ainda que dentro da mesma profissão, tentarmos captar a perspectiva dos Administradores atuantes nestas diferentes áreas temáticas da Administração. Como estratégia para composição da amostra, foram contatadas diversas associações profissionais (como conselhos de classe de âmbito estadual e federal, por exemplo: os Conselhos Regionais de Administração, CRA, e o Conselho Federal de Administração, CFA) e sindicatos; e, ainda instituições de Ensino Superior. Procuramos contactar profissionais da Administração com atuação tanto na área acadêmica quanto na prática (ou seja, com atuação na área aplicada). Em seguida, foi feita uma abordagem direta aos profissionais através dos e-mails profissionais disponíveis em sites institucionais (como por exemplo aos docentes). E, por último, foram contatados os egressos do curso de Administração de várias universidades (com a autorização e colaboração destas instituições). Houve uma preocupação em contatar administradores das mais variadas áreas de atuação, a fim de formar uma amostra que expressasse as várias facetas do administrador. Quanto às regiões, contamos com a participação de profissionais do Norte, Nordeste, Sudeste e Sul do Brasil através das instituições já referidas. Apesar de contarmos com a divulgação nacional através do Conselho Federal de Administração, não podemos confirmar se tivemos a participação de profissionais do Centro-Oeste, pois não foi feita uma pergunta sobre a localização geográfica dos profissionais entre as questões sociodemográficas. Para participar, contudo, era necessário que as seguintes condições fossem atendidas: ter pelo menos seis meses de experiência profissional; estar em funções nas quais tivessem um vínculo financeiro, ou seja, com remuneração; e ter formação em Administração. $\mathrm{O}$ objetivo não foi avaliar nenhuma organização em particular, mas sim a percepção dos profissionais sobre o seu próprio trabalho.

Os questionários foram respondidos em uma plataforma online. Ao ser contactado, o participante era informado sobre o estudo e convidado a acessar ao protocolo de pesquisa online. Ao clicar no link, o participante encontrava o termo de consentimento livre e esclarecido. Em caso de dúvidas, era facultado os contatos da equipe de pesquisa (que poderia ser contactada de várias formas). Após esta leitura, o participante encontrava uma caixa de seleção como forma de confirmar que concordava em participar do estudo. O sigilo e o anonimato das respostas foram garantidos, e os participantes foram informados de que os resultados serviriam apenas para fins de pesquisa e que poderiam interromper a participação a qualquer momento. A pesquisa foi desenvolvida no Brasil e atendeu ao Código de Ética e Disciplina dos Profissionais de Administração (Conselho Federal de administração, CFA, 2018) e ao Código de Ética do Conselho Federal de Psicologia (CFP, 2014). A tarefa durava cerca de 20 minutos. 


\section{Procedimentos de Análise de Dados}

As análises estatísticas foram realizadas com o software IBM SPSS Statistical package (versão 22.0, IBM Corporation, 2013) para o sistema operacional Windows. Inicialmente, nas análises preliminares foram examinadas as características descritivas da amostra e dos itens. As medidas de tendência central (média e desvio padrão) e propriedades distributivas (assimetria e curtose) foram calculadas para cada item do QTD para avaliar a sensibilidade psicométrica dos itens. Os valores de assimetria não excederam | 1,63 | e para curtose, a pontuação mais alta foi | 2,54 |. Essas pontuações são consistentes com as premissas de normalidade da amostra (Kline, 2011; Maroco, 2014). Em seguida, para examinar a confiabilidade, as consistências internas das escalas foram verificadas através do cálculo do coeficiente Alfa de Cronbach (Maroco \& Garcia-Marques, 2006). Foram realizadas Análises Fatoriais Exploratórias (AFEs) preliminares apenas para confirmar a estrutura fatorial dos 3 instrumentos utilizados (estas análises não estão incluídas neste documento por uma limitação de espaço, entretanto estão disponíveis para consulta junto aos autores). O QTD (Ferraro et al., 2018) e o ESV (Gouveia et al., 2009) apresentaram a mesma estrutura já previamente relatada, entretanto, a QST (Carlotto \& Câmara, 2008) apresentou algumas diferenças (relatadas mais adiante na seção 'Resultados'). Posteriormente, as interações entre as variáveis em estudo foram avaliadas com cálculo das correlações bivariadas de Pearson entre as dimensões do Trabalho Digno (QTD), as dimensões da escala de Satisfação com o Trabalho (QST) e a Satisfação com a Vida (ESV). Finalmente, foi realizada a análise das correlações canônicas entre as dimensões do TD e as dimensões da QST e a ESV para examinar os mecanismos subjacentes entre essas variáveis.

Valores omissos. No presente estudo, não temos valores omissos ou ausentes nos dados coletados dos questionários conceituais, pois a plataforma eletrônica permite exigir que todos os itens sejam respondidos.

\section{Resultados}

Os resultados são apresentados em três partes principais. Inicialmente, são indicadas as pequenas diferenças encontradas entre o comportamento do QST relatado por Carlotto e Câmara (2008) e a atual aplicação através da comparação das AFEs realizadas. Em seguida, apresentamos os resultados das correlações bivariadas de Pearson entre as dimensões do Trabalho Digno (QTD), as dimensões da escala de Satisfação com o Trabalho (QST) e a Satisfação com a Vida (ESV), que poderão ser observados na Tabela 2 (a seguir). Por último, apresentamos os resultados da análise das correlações canônicas entre os fatores de TD e as dimensões da Satisfação com o Trabalho e com a Vida, cujos detalhes podem ser consultados nas Tabelas 3 e 4 (mais adiante).

\section{Análise Fatoriais Exploratórias (AFEs)}

Preliminarmente, foram realizadas Análises Fatoriais Exploratórias (AFEs) com o objetivo de confirmar a estrutura fatorial dos 3 instrumentos utilizados (análises não incluídas neste documento por uma limitação de espaço, entretanto disponíveis para consulta junto aos autores). O QTD (Ferraro et al., 2018) e o ESV (Gouveia et al., 2009) apresentaram a mesma estrutura previamente relatada em seus estudos de validação, entretanto a QST (Carlotto \& Câmara, 2008) apresentou algumas diferenças que passamos a relatar.

$\mathrm{Na}$ atual amostra $(N=292)$, com administradores(as) brasileiros(as), foram encontrados os mesmos 3 fatores descritos por
Carlotto e Câmara (2008). Entretanto, diferentemente do estudo destas autoras, todos os itens atingiram cargas fatoriais superiores ao 0,50 (considerado o ponto de corte para manutenção ou exclusão do item). Além disso, nenhum item saturou em mais de um fator. O conjunto dos resultados obtidos fez-nos manter os 23 itens (diferindo do estudo de Carlotto \& Câmara, 2008, no qual os itens 4, 11 e 12 precisaram sair da forma final do questionário por terem saturação fatorial simultânea em mais de um fator). Outra diferença foi a disposição dos fatores: enquanto o fator 1 da presente amostra (Satisfação com as relações hierárquicas) correspondeu ao fator 1 da amostra de Carlotto e Câmara (2008; com os mesmos 11 itens); o fator 2 do presente estudo (nomeado como Satisfação intrínseca no trabalho; com 7 itens) correspondeu ao fator 3 do estudo prévio de Carlotto e Câmara (2008), denominado por elas Satisfação intrínseca no trabalho, e composto por apenas 4 itens; e, o fator 3 da presente amostra correspondeu ao fator 2 da amostra de Carlotto e Câmara (2008) em referência à Satisfação com o ambiente físico de trabalho. $\mathrm{O}$ fator 2 do estudo atual contou com os 3 itens que anteriormente foram retirados do instrumento no estudo prévio de Carlotto e Câmara (2008). Quanto à alteração da posição dos fatores 2 e 3, muito provavelmente relaciona-se com pequenas flutuações na carga fatorial em função de diferenças nos perfis das amostras. Destacamos a relevância de terem sido encontrados os mesmos 3 fatores previamente descritos pelas autoras referidas (Carlotto \& Câmara, 2008).

\section{Correlações Bivariadas}

As médias, desvios padrão e coeficientes Alfa de Cronbach do TD Global e de suas dimensões para a amostra total $(N=292)$ podem ser consultados na Tabela 2 , bem como as correlações de Pearson do TD Global e seus fatores com a satisfação com o trabalho (e suas dimensões) e com a satisfação com a vida.

Todas as correlações foram estatisticamente significativas no nível 0,01 e positivas entre: (a) TD Global e as dimensões do TD, (b) entre cada par de dimensões de TD, (c) entre o TD global e todas as suas dimensões e a Satisfação com o trabalho e todas as suas dimensões e a Satisfação com a vida. A correlação mais elevada ocorreu entre a dimensão de Princípios e valores fundamentais no trabalho (TD1) e a Satisfação com as relações hierárquicas (fator 1 da Satisfação com o trabalho, QST1): 0,87, seguida da correlação entre TD1 e a Satisfação-com-o-trabalho-Global com 0,86. Damos destaques as duas interações em função de mostrarem uma relação forte entre o TD1 e a Satisfação com o Trabalho. O TD Global e a satisfação com o trabalho em geral apresentam uma forte correlação de 0,84 . Há ainda uma correlação mais forte $(0,95)$ do próprio QST1 com a Satisfação-com-o-trabalho-Global. Isso justifica o destaque dado às outras duas correlações. A correlação menos intensa e, mesmo assim, com valores de correlações moderadas apresenta-se entre Tempo e Carga de Trabalho Adequados (TD2) e a Satisfação com o ambiente físico (fator $3 \mathrm{da}$ Satisfação com o trabalho, QST3): 0,29.

\section{Análise de Correlações Canônicas (ACC)}

A ACC pode ser entendida como uma extensão da análise de regressão múltipla (Meyers et al., 2017). Na regressão múltipla, usamos um conjunto de variáveis independentes para prever o valor de uma única variável dependente (ou medida de critério). Quando aplicamos a ACC, usamos um conjunto de variáveis independentes para prever um conjunto de variáveis dependentes. A ACC também pode ser referida como uma regressão múltipla multivariada (Meyers et al., 2017). A ACC é um design potencialmente mais poderoso que a regressão múltipla, da mesma forma 
Estatísticas descritivas e correlações bivariadas entre Trabalho Digno, Satisfação com o Trabalho e Satisfação com a Vida $(\mathrm{N}=292)$

\begin{tabular}{|c|c|c|c|c|c|c|c|c|c|c|c|c|c|c|c|c|}
\hline Measure & $M$ & $S D$ & $\alpha$ & 1 & 2 & 3 & 4 & 5 & 6 & 7 & 8 & 9 & 10 & 11 & 12 & 13 \\
\hline 1. TD Global & 112,24 & 21,04 & ,95 & 1,00 & & & & & & & & & & & & \\
\hline $\begin{array}{l}\text { 2. Princípios e Valores } \\
\text { Fundamentais no Trabalho }\end{array}$ & 21,48 & 5,03 & 0,89 & $0,81 * *$ & 1,00 & & & & & & & & & & & \\
\hline $\begin{array}{l}\text { 3. Tempo e Carga de } \\
\text { Trabalho Adequadas }\end{array}$ & 14,18 & 3,83 & 0,88 & $0,70 * *$ & $0,48^{* *}$ & 1,00 & & & & & & & & & & \\
\hline $\begin{array}{l}\text { 4. Trabalho Realizante e } \\
\text { Produtivo }\end{array}$ & 20,68 & 4,06 & 0,87 & $0,81 * *$ & $0,66^{* *}$ & $0,50 * *$ & 1,00 & & & & & & & & & \\
\hline $\begin{array}{l}\text { 5. Remuneração } \\
\text { significativa para o } \\
\text { exercício da cidadania }\end{array}$ & 14,59 & 4,25 & 0,94 & $0,77 * *$ & $0,49 * *$ & $0,47 * *$ & $0,60 * *$ & 1,00 & & & & & & & & \\
\hline 6. Proteção social & 10,74 & 4,06 & 0,85 & $0,67 * *$ & $0,36^{* *}$ & $0,38 * *$ & $0,38 * *$ & $0,55^{* *}$ & 1,00 & & & & & & & \\
\hline 7. Oportunidades & 15,40 & 3,34 & 0,74 & $0,71 * *$ & $0,58 * *$ & $0,48 * *$ & $0,62 * *$ & $0,37 * *$ & $0,33 * *$ & 1,00 & & & & & & \\
\hline 8. Saúde e Segurança & 15,17 & 3,54 & 0,89 & $0,74 * *$ & $0,59^{* *}$ & $0,41 * *$ & $0,46 * *$ & $0,53 * *$ & $0,48 * *$ & $0,40 * *$ & 1,00 & & & & & \\
\hline $\begin{array}{l}\text { 9. Satisfação com o } \\
\text { Trabalho }\end{array}$ & 84,36 & 18,59 & 0,96 & $0,84 * *$ & $0,86 * *$ & $0,53 * *$ & $0,70 * *$ & $0,55^{* *}$ & $0,44 * *$ & $0,58 * *$ & $0,65^{* *}$ & 1,00 & & & & \\
\hline $\begin{array}{l}\text { 10. Satisfação com as } \\
\text { relações hierárquicas } \\
\text { (QST1) }\end{array}$ & 38,73 & 10,24 & 0,95 & $0,76 * *$ & $0,87 * *$ & $0,49 * *$ & $0,62 * *$ & $0,44 * *$ & $0,38 * *$ & $0,56 * *$ & $0,55^{* *}$ & $0,95 * *$ & 1,00 & & & \\
\hline $\begin{array}{l}\text { 11. Satisfação intrínseca no } \\
\text { trabalho (QST2) }\end{array}$ & 25,73 & 6,03 & 0,90 & $0,84 * *$ & $0,75^{* *}$ & $0,58 * *$ & $0,79 * *$ & $0,66 * *$ & $0,46 * *$ & $0,53 * *$ & $0,54 * *$ & $0,89 * *$ & $0,78^{* *}$ & 1,00 & & \\
\hline $\begin{array}{l}\text { 12. Satisfação com o } \\
\text { Ambiente Físico (QST3) }\end{array}$ & 19,90 & 4,66 & 0,93 & $0,58 * *$ & $0,56 * *$ & $0,29 * *$ & $0,42 * *$ & $0,37 * *$ & $0,32 * *$ & $0,39 * *$ & $0,70^{* *}$ & $0,75^{* *}$ & $0,59 * *$ & $0,53 * *$ & 1,00 & \\
\hline 13. Satisfação com a Vida & 25,34 & 5,58 & 0,89 & $0,74 * *$ & $0,54 * *$ & $0,53 * *$ & $0,66 * *$ & $0,70 * *$ & $0,48 * *$ & $0,50 * *$ & $0,43 * *$ & $0,62 * *$ & $0,53 * *$ & $0,71^{* *}$ & $0,38 * *$ & 1,00 \\
\hline
\end{tabular}

Nota. as correlações significativas estão em negrito. ** A correlação é significativa para $p=0,01$ (1 tailed).

que um design de regressão múltipla é potencialmente mais poderoso que a regressão linear simples (Meyers et al., 2017). Segundo Hair, Anderson, Tatham, \& Black (2005), “a correlação canônica é tida como o modelo geral no qual muitas outras técnicas multivariadas são baseadas, pois ela pode utilizar tanto dados métricos quanto não-métricos para variáveis dependentes ou independentes” (p. 361). Após examinar correlações simples e múltiplas, a ACC nos permite investigar a relação multivariada entre as dimensões do TD e as demais variáveis em estudo.

Realizamos a ACC com o objetivo de examinar as interações subjacentes entre os fatores de TD (variáveis independentes ou preditoras) e um segundo grupo de variáveis dependentes no qual colocamos as dimensões da Satisfação com o Trabalho (3 fatores) e a Satisfação com a Vida (uma escala unidimensional). As análises foram realizadas, também, com o IBM SPSS Statistics versão 22, com um pacote de extensão denominado STATS CANCORR (IBM Corporation, 2015). Para interpretar as funções canônicas, utilizamos a abordagem de cargas canônicas, com exame da magnitude dos coeficientes de correlações estruturais canônicas (também conhecidos como cargas canônicas, Hair et al., 2005) para cada interação em variáveis canônicas (Hair et al., 2005; Meyers et al., 2017). Os resultados estão resumidos nas Tabelas 3 e 4.

A relação entre os conjuntos de variáveis mostrou quatro Tabela 3

Resultados da análise das correlações canônicas das interações entre os fatores de TD e Satisfação com a Vida e com o Trabalho

\begin{tabular}{|c|c|c|c|c|c|c|}
\hline $\begin{array}{l}\text { Função } \\
\text { canônica }\end{array}$ & $\begin{array}{l}\text { Autovalor } \\
\text { (Eigenvalue) }\end{array}$ & $\begin{array}{l}\text { Percentual } \\
\text { de } \\
\text { variância } \\
\text { explicada }\end{array}$ & $\mathrm{Rc}$ & Rc2 & $\begin{array}{l}\text { Wilks's } \\
\text { Lambda }\end{array}$ & $F$ \\
\hline \multirow{4}{*}{$\begin{array}{l}1 \\
2\end{array}$} & 4,93 & 77,29 & 0,91 & 0,82 & 0,06 & $44,23^{* * *}$ \\
\hline & 0,94 & 14,67 & 0,70 & 0,49 & 0,33 & $21,00^{* * *}$ \\
\hline & 0,43 & 6,81 & 0,55 & 0,30 & 0,65 & $13,79 * * *$ \\
\hline & $\overline{0,08}$ & $\overline{1,22}$ & 0,27 & 0,07 & $\overline{0,93}$ & $5,54 * * *$ \\
\hline
\end{tabular}

Nota. $* \varrho<0,05 ; * * \varrho<0,01 ; * * * \varrho<0,001$. Rc $=$ valor da correlação canônica; Rc2 = valor da correlação canônica ao quadrado (expressa a variância compartilhada entre os conjuntos de variáveis).
Tabela 4

Funções canônicas interpretáveis $(\mathrm{N}=292)$

\begin{tabular}{|c|c|c|c|}
\hline \multirow[b]{2}{*}{ Variáveis } & \multicolumn{3}{|c|}{ Cargas canônicas } \\
\hline & $\begin{array}{l}\text { Primeira } \\
\text { função } \\
\text { canônica }\end{array}$ & $\begin{array}{l}\text { Segunda } \\
\text { função } \\
\text { canônica }\end{array}$ & $\begin{array}{l}\text { Terceira } \\
\text { função } \\
\text { canônica }\end{array}$ \\
\hline \multicolumn{4}{|l|}{ Grupo 1: Fatores do trabalho digno } \\
\hline $\begin{array}{l}\text { Princípios e valores fundamentais } \\
\text { no trabalho }\end{array}$ & $-0,92$ & $-0,35$ & $-0,15$ \\
\hline $\begin{array}{l}\text { Tempo e carga de trabalho } \\
\text { adequadas }\end{array}$ & $-0,65$ & 0,22 & $-0,05$ \\
\hline Trabalho realizante e produtivo & $-0,85$ & 0,29 & 0,05 \\
\hline $\begin{array}{l}\text { Remuneração significativa para o } \\
\text { exercício da cidadania }\end{array}$ & $-0,71$ & 0,47 & 0,25 \\
\hline Proteção Social & $-0,53$ & 0,18 & 0,17 \\
\hline Oportunidades & $-0,66$ & $-0,06$ & 0,00 \\
\hline Saúde e segurança & $-0,66$ & $-0,26$ & 0,69 \\
\hline \multicolumn{4}{|l|}{$\begin{array}{l}\text { Grupo 2: demais variáveis associadas à } \\
\text { satisfação com a vida e com o trabalho }\end{array}$} \\
\hline \multicolumn{4}{|l|}{ Satisfação com o Trabalho } \\
\hline $\begin{array}{l}\text { Satisfação com as relações } \\
\text { hierárquicas (QST1) }\end{array}$ & $-0,91$ & $-0,38$ & $-0,18$ \\
\hline $\begin{array}{l}\text { Satisfação intrínseca no trabalho } \\
\text { (QST2) }\end{array}$ & $-0,95$ & 0,19 & 0,03 \\
\hline $\begin{array}{l}\text { Satisfação com o ambiente físico } \\
\text { (QST3) }\end{array}$ & $-0,62$ & $-0,39$ & 0,68 \\
\hline Satisfação com a vida & $-0,78$ & 0,44 & 0,10 \\
\hline
\end{tabular}

funções canônicas estatisticamente significativas (como pode ser observado na Tabela 3). Nossas análises concentraram-se em apenas as três primeiras funções canônicas por serem aquelas que atingiram valores não triviais de correlações canônicas, ou seja, Rc superior a 0,30 (Pituch \& Stevens, 2016). O outro indicador estatístico que atesta a relevância de nossas funções canônicas é o Lambda de Wilks $(\lambda)$ que "representa a variação inexplicada pelo modelo e, portanto, 1 - $\lambda$ produz o tamanho total do efeito do 
modelo" (Sherry \& Henson, 2005, p. 48). O Wilks $\lambda=0,06$ indica que o modelo completo explica $94 \%$ da variação compartilhada entre os dois conjuntos de variáveis. Para cada função canônica, a percentagem de variância compartilhada nos mostra que a primeira função canônica explica aproximadamente $77,3 \%$ da variância compartilhada, a segunda função canônica explica 14,7\%, e a terceira função canônica explica adicionalmente $6,8 \%$ da variância compartilhada. Juntas, as três funções canônicas acumulam 98,8\% da variância explicada (valores baseados nos autovalores, Meyers et al., 2017). Para cada conjunto de variáveis, na primeira função canônica, os fatores TD explicaram $82 \%$ da variação do conjunto 2 (que reúne a Satisfação com a Vida e a Satisfação com o Trabalho). $\mathrm{Na}$ segunda função canônica, os fatores TD explicaram $49 \%$ da variação do conjunto 2 . Finalmente, na terceira função canônica, os fatores de TD explicaram $30 \%$ da variância do conjunto 2 (veja as Tabelas 3 e 4, estes valores são baseados em Rc2, Meyers et al., 2017).

Os resultados sugerem que a interação entre as dimensões do TD e a Satisfação com a Vida e com o Trabalho é explicada principalmente por três mecanismos, que a interpretação das funções canônicas ajuda a esclarecer. A primeira função canônica apresentou o mesmo padrão de associação observado nas correlações de Pearson, com todos os fatores do TD associados, em geral, a todas as demais variáveis. Expressa uma primeira função canônica substancial, seguida por outras duas mais simples. A interpretação é baseada nos valores mais elevados das cargas canônicas. Para estabelecer o ponto de corte, nos baseamos em um valor mais conservador (igual ou superior a 0,45, como Joo \& Nimon, 2014, p. 579). Entretanto, fomos flexíveis para a interpretação da segunda função canônica, na qual observa-se que, no segundo grupo de variáveis, apenas a Satisfação com a Vida aproximou-se deste valor ao atingir a carga canônica e 0,44 (discutido mais adiante).

A primeira função canônica mostra que todos os fatores do TD se correlacionam fortemente e na mesma direção com a Satisfação com a Vida e as dimensões da Satisfação com o Trabalho. A relação com a Satisfação com a Vida sugere que os contextos de trabalho nos quais o TD é percebido pelos trabalhadores promovem a Satisfação com a Vida. Além disso, contextos de trabalho com elevada percepção do TD também parecem estar relacionados com todas as dimensões da Satisfação com o Trabalho, acentuadamente com os Fatores 1 (Satisfação com as relações hierárquicas) e 2 (Satisfação intrínseca no trabalho). Entre as dimensões do TD, os Princípios e valores fundamentais no trabalho (TD1), o trabalho realizante e produtivo (TD3) seguido pela remuneração significativa para o exercício da cidadania (TD4) foram as dimensões que mais se destacaram nesta função canônica. Ou, dito de outra maneira, a falta dos fatores do TD parece contribuir para diminuir a satisfação com a vida e com o trabalho. Essas interpretações ficam reforçadas pela análise de correlações de Pearson (anteriormente mencionadas).

A segunda função canônica relaciona positivamente a Remuneração significativa para o exercício da cidadania (TD4) com a Satisfação com a Vida. Neste caso, apesar de nos propormos a utilizar como ponto de corte o valor de 0,45 de carga canônica, abrimos uma exceção, em função do valor ter se aproximado bastante deste ponto de corte com 0,44. Podemos interpretar esses resultados como contextos de trabalho onde os profissionais percebem que há uma remuneração adequada que permite uma vida com bem-estar para o próprio trabalhador e para aqueles que dele dependem, a satisfação com a vida é maior.

A terceira função canônica relaciona positivamente a saúde e segurança no trabalho (TD7) com ao fator satisfação com o ambiente físico de trabalho (QST3). Esta é uma função canônica com o tema dedicado às condições físicas do ambiente profissional.
Interpretamos esses resultados como expressão de que em ambientes de trabalho onde os profissionais percebem que há saúde e segurança - ou seja, a percepção de estar seguro e protegido de riscos à saúde física, com acesso a tudo o que é preciso para manter a integridade física no trabalho e condições ambientais também seguras -, há satisfação com o ambiente físico.

Em síntese, a principal conclusão desta seção de resultados é que, para os administradores da nossa amostra, os temas do TD (representados nestas análises pelas suas 7 dimensões) têm relevância na promoção da satisfação com a vida e com o trabalho (de maneiras diferentes nas correlações canônicas estatisticamente significativas encontradas): Princípios e valores fundamentais no trabalho (TD1), trabalho realizante e produtivo (TD3), Remuneração significativa para o exercício da cidadania (TD4) e Saúde e segurança (TD7) tiveram um papel de destaque no efeito observado, ora ao influenciar mais a satisfação com a vida em geral (como na segunda correlação canônica), ora ao influenciar mais a satisfação com o trabalho em alguma características específica, como o ambiente físico representado pelo fator 3 (como na terceira correlação canônica).

\section{Discussão}

O presente estudo, partiu de duas questões iniciais orientadoras (ou bases lógicas) que foram suportadas com a verificação da interação positiva que foi encontrada entre o TD, a satisfação com o trabalho e com a vida. O TD mostrou-se como um importante promotor da satisfação com o trabalho e com a vida. A utilização da análise de correlações canônicas nos auxiliou a verificar mecanismos subjacentes que se tornaram evidentes ao observamos a interação entre os dois conjuntos de variáveis (independentes e dependentes) simultaneamente. $\mathrm{Na}$ avaliação do impacto do TD sobre a satisfação com o trabalho e com a vida, três funções canônicas estatisticamente significativas foram interpretadas.

A primeira função canônica apresentou uma correlação positiva e forte entre todas as dimensões do TD e as dimensões de Satisfação com o Trabalho e a Satisfação com a Vida. Em termos de interpretação, esta correlação sugere que para os profissionais da Administração da nossa amostra a percepção de realizar um TD está associada à percepção de satisfação com o trabalho (em todas as suas dimensões) e com a percepção de satisfação com a vida.

Princípios e valores fundamentais no trabalho (TD1), Trabalho realizante e produtivo (TD3) e a Remuneração significativa para o exercício da cidadania (TD4) foram os fatores do TD que mais se destacaram no papel de promotores da satisfação com o trabalho e com a vida. Quanto aos fatores da satisfação com o trabalho as dimensões da Satisfação com as relações hierárquicas e intrínseca no trabalho (QST1 e 2) foram aquelas com cargas mais elevadas assim como a Satisfação com a Vida.

A conexão entre ética organizacional, enquanto princípio e valor fundamental, e satisfação com o trabalho já havia sido previamente destacada através de um estudo com uma amostra de administradores realizado por Koh e Boo (2001), o que reforça a ideia que ambientes de trabalho que promovam e recompensem o comportamento ético favorecem a satisfação com o trabalho como um todo. Ter um trabalho "significativo e pessoalmente interessante", como apontado por Bergmann (1981), se destaca como um fator promotor da satisfação com o trabalho no presente estudo. Tal percepção corrobora com Doussiotis e Austin (2007), que reforçam que existe um interesse cada vez maior em trabalhos que sejam significativos por parte dos trabalhadores, como identificado na amostra de administradores aqui pesquisada.

A existência de um bom relacionamento hierárquico também é um fator relevante para os administradores. Neste sentido, Koh 
e Boo (2001) destacam que os líderes organizacionais podem influenciar os resultados organizacionais. Pradhan et al. (2019) enfatizam que desenvolver a satisfação dos trabalhadores é de suma relevância aos aspectos pessoais e profissionais dos mesmos. Além disso, Droussotis \& Austin (2007) defendem que a satisfação no trabalho proporciona um aumento no que se refere ao desempenho. No campo da Administração, tais conceitos assumem uma importância ainda maior, pois os administradores são, na maioria dos casos, agentes fundamentais para orquestrar o desenvolvimento organizacional.

O papel de destaque para a dimensão Remuneração significativa para o exercício da cidadania (TD4) fica ainda mais evidente na segunda função canônica onde aparecem TD4 e a Satisfação com a Vida. TD4 relaciona-se com uma vida que pode ser vivida com dignidade e autonomia e a percepção de uma remuneração justa pelo trabalho desempenhado. Também, está associado à possibilidade de sentir bem-estar pessoal e profissional a partir do que se recebe pelo trabalho realizado e oferecer bem-estar para aqueles que dele(a) dependem. Para os participantes do estudo, ter uma remuneração adequada, que proporcione uma vida digna e bem-estar a si mesmo e aos seus dependentes é um fator relevante para a satisfação com a vida. É possível sintetizar a interpretação desta função canônica ao referir que o salário (enquanto recompensa material), benefícios ou até mesmo recompensas intangíveis (como o reconhecimento no local de trabalho e o investimento no desenvolvimento pessoal e profissional dos trabalhadores) são fundamentais, do ponto de vista dos administradores da nossa amostra, para a satisfação com a vida.

Para os administradores do nosso estudo, a remuneração pode promover a satisfação com a vida pois através dela, os objetivos de vida podem ser alcançados. Esta relação entre remuneração e satisfação com a vida foi previamente apontada por Vieira et al. (2007). Logo, dar atenção ao reconhecimento, bem como promover uma remuneração justa e adequada, devem ser premissas fundamentais do administrador na atualidade, uma vez que a satisfação global com o trabalho é um dos principais componentes da satisfação geral com a vida (Zalewska,1999).

A terceira correlação canônica interpretada diz respeito a uma positiva e intensa correlação canônica entre TD7 (Saúde e Segurança), e o QST3 (Satisfação com o ambiente físico). Uma vez mais, uma correlação que faz sentido intuitivamente, afinal espera-se que um ambiente de trabalho que disponibiliza para o trabalhador condições de saúde e segurança adequadas, além de estar alinhado com um trabalho digno, muito provavelmente representa uma contribuição para a satisfação com o ambiente físico do trabalho. Também, é possível inferir que o investimento de uma organização na saúde e segurança dos seus trabalhadores promove a satisfação destes com o ambiente físico no qual trabalham.

Para o caso dos administradores, as funções canônicas encontradas são relevantes não apenas em nível individual mas, também, em nível organizacional, uma vez que estes profissionais podem atuar profissionalmente para que as condições de TD global sejam valorizadas.

A pesquisa sobre o TD através perspectiva da Psicologia das Organizações, do Trabalho e dos Recursos Humanos (POTRH) é ainda relativamente recente. Em função disso, ainda existem poucos estudos empíricos que possam oferecer informações e padrões comparativos na interpretabilidade dos achados (Ferraro et al., 2017). No entanto, os resultados podem projetar novas e melhores práticas de trabalho, além do desenvolvimento de estratégias e políticas de gerenciamento dos recursos humanos nas organizações. Isso é especialmente relevante para o contexto atual da Administração e, em especial para a Administração aplicada na Gestão dos Recursos Humanos (GRH).
Ling, Ning, Chang e Zhang (2018) destacam as cinco principais atividades da GRH que promovem uma alta performance: (a) a atração de talentos e sua manutenção em uma organização através de (b) (re)desenho do trabalho, do (c) treinamento e desenvolvimento de pessoas no trabalho, (d) de um sistema de recompensas adequado, e (e) de uma gestão do desempenho que potencialize as capacidades individuais e os resultados grupais e organizacionais. Eles referem que as práticas de GRH tem uma associação positiva e significativa com a satisfação com o trabalho. Entre aquelas práticas identificadas por eles e que estão em alinhamento com o que encontramos no nosso estudo enfatizamos: (a) a oportunidade de treinamento e desenvolvimento, mesmo que em cumprimento de exigências legais, com ênfase nos treinamentos em Saúde e Segurança, principalmente as regulamentações afins ao setor do estudo; (b) o investimento em pacotes de recompensas como benefícios relacionados aos planos/seguros de saúde, subsídio de transporte e subsídio de telefonia móvel. Ling et al. (2018) destacam ainda que é relevante dar atenção para os salários, promoção de oportunidades, pacotes de bem-estar e o pacote de recompensas ou benefícios em geral. A retenção de um staff de alto desempenho pode depender da atenção especial ao tema da remuneração/compensação e das promoções; e ainda, (c) na gestão do desempenho, Ling et al. (2018) destacam a importância de dar e receber feedback como elemento essencial para promover um ambiente de confiança e respeito. Eles referem alguns sistemas como formas de recepção de feedback: por exemplo, em sistemas online, através de respostas verbais presenciais, e com o recurso das caixas de coleta de sugestões. Segundo eles, os sistemas que oferecem feedback anonimamente parecem gerar mais satisfação com o trabalho do que outras opções. Em especial, receber feedback da avaliação de desempenho aumenta a satisfação com o trabalho e com as práticas de GRH nos administradores do estudo. Segundo Ling et al. (2018), este tipo de feedback contribuiu aos administradores (do referido estudo) em entender as áreas que tinham se saído bem e aquelas que precisavam melhorar e o que poderia ser feito para progredirem na carreira de modo planejado.

Nosso estudo sugere como temáticas relevantes para as políticas e práticas de GRH fundamentadas no trabalho digno: primeiro, uma atenção com todas as facetas do trabalho digno por estarem todas relacionadas com a promoção da satisfação com o trabalho e com a vida (como evidenciado em nossa primeira correlação canônica). Em seguida, nossa segunda correlação canônica nos sugere que uma atenção especial ao sistema de remuneração e recompensas que se fundamente nos princípios de um trabalho digno também podem maximizar, em especial, a satisfação com a vida. A junção de sistemas de avaliação de desempenho e sistemas de recompensas fortalecidos por feedback e clareza de critérios parece ser um elemento relevante para a satisfação com o trabalho (como anteriormente verificado por Garcia-Izquierdo et al., 2012) e com a vida. Finalmente, as políticas e práticas de RH voltadas para a promoção da saúde e da segurança no trabalho podem ser concretizadas através de treinamentos e demais formas de atualizações sobre as regulamentações vigentes, por exemplo: através de uma newsletter interna ou de painéis internos que divulguem atempadamente o total de dias sem acidentes de trabalho (prática comumente adotada em tantas organizações industriais). Aparentemente, o conjunto destas iniciativas parecem ser a melhor alternativa para maximizar a satisfação com o trabalho e com a vida.

As três funções canônicas chamam a atenção para o desenvolvimento de abordagens e estratégias mais humanas, que respeitem os direitos e aspirações dos trabalhadores, e devem ser levadas em consideração nos processos decisórios dos Administradores. Assim, a incorporação do TD deve ser uma prioridade aos atuais gestores, pois melhores condições de trabalho e remuneração 
geralmente estão associadas ao desempenho, uma vez que promovem satisfação no trabalho e, consequentemente, satisfação com a vida em seus aspectos mais globais.

Uma contribuição adicional do nosso estudo relaciona-se a importância do trabalho (em especial o trabalho digno) para a vida das pessoas. Um interessante documento da ILO (2001a) reúne vários discursos do Diretor-Geral Juan Somavía (função exercida entre 1999 e 2012). Ao consultar estes documentos, é possível compreender o trabalho digno como um "people-centred concept" (p. v, 15, 29). Segundo Somavía (ILO, 2001a), o trabalho digno é "the most deeply felt aspiration of people in all societes, developed and developing" ["A aspiração mais profunda das pessoas em todas as sociedades, desenvolvidas e em desenvolvimento"] (p. 17). O motivo disto é porque é através do trabalho que as pessoas expressam as suas necessidades e encontram recursos para suprir as suas necessidades. Ele ainda acrescenta:

se você sair, for para as ruas ou para os campos e perguntar para as pessoas o que elas querem, em meio às incertezas que a globalização trouxe sobre todos nós, a resposta é, trabalho. Trabalho para suprir as necessidades das suas famílias em termos de saúde e segurança, educação para suas crianças, e oferecer a eles/as uma renda segura depois da aposentadoria, trabalho no qual eles/as possam ser tratados decentemente e seus direitos básicos sejam respeitados. É disso que se trata o trabalho digno. E se trata de alcançar a todos. Se você pensar sobre isto, todo mundo trabalha. Parte desse trabalho é feito em grandes empresas, parte é informal e muito, porque é feito em casa, geralmente por mulheres, nem é reconhecido como trabalho, mas todas essas pessoas têm direito a um trabalho digno. (ILO, 2001a, p. 17, tradução nossa)

Em outro discurso, Somavía (ILO, 2001a, p. 66) relata que o trabalho digno é resultado de suas conversas com muitas pessoas através de largos anos, inclusive na sua preparação para o World Summit for Social Development (em Copenhagen). Ele conta que lá, perguntou o que poderia ser a nossa resposta [conjunta] para os problemas da pobreza e da exclusão e, segundo ele, a resposta geral tem sido "trabalho":

O trabalho oferece uma saída para a pobreza e pode permitir que os trabalhadores dêem um passo em direção à integração. Oferece os meios de educar os filhos e construir uma família, de ser respeitado pelos outros e, se obedecer às regras, de ter uma pensão. E então me pergunto: é tão revolucionário tentar atender a essas necessidades? Por que deveria ser tão difícil? Podemos realmente dizer às pessoas para esquecer estas ambições porque elas nunca se tornarão realidade? Responder a estas perguntas é uma tarefa fundamental para a OIT no ano 2000 e além. (ILO, 2001a, p. 66, tradução nossa)

Ainda a refletir sobre a relevância do tema para as pessoas, Somavía (ILO, 2008) argumentou que o trabalho digno é uma demanda democrática fundamental e citou alguns questionários aplicados em diversos países para fortalecer esta importância. O Pew Global Attitudes Survey de 2007, aplicado em 47 países, sugeria que a satisfação com o trabalho tem um papel importante na explicação da felicidade geral (ou seja, na satisfação com a vida como um todo). O The World Values Survey ( $4^{a}$ onda que integrou documentos de 1981 a 2004), e contou com as contribuições de 79 países, destacou os atributos mais desejados em um trabalho/emprego. Os três atributos mais citados foram: uma renda decente, um vínculo de trabalho seguro e qualidades intrínsecas do trabalho, tais como: um trabalho que esteja alinhado com as habilida- des do trabalhador; um trabalho que seja interessante e ofereça ao indivíduo oportunidades para alcançar ou realizar alguma coisa. A ILO (2008) destacou que esta convergência de pontos de vista não era propriamente uma novidade e que a própria experiência acumulada (pela ILO) mostrava que as pessoas buscam "ir em frente" na vida e construir um futuro melhor para suas famílias e para si próprios. Estes, e ainda outros inquéritos internacionais citados, foram apresentados como fontes que revelavam que o trabalho digno e produtivo é uma prioridade para as pessoas em todo o mundo, seja em países em desenvolvimento ou industrializados (ILO, 2008, p. 14-15).

Ao considerarmos os objetivos da OIT/ILO, e sua visão do trabalho digno enquanto uma aspiração universal dos trabalhadores (ILO, 2001b), o presente estudo representa uma pequena contribuição para conscientização das pessoas a respeito do trabalho digno. O desenvolvimento de cada vez mais estudos sobre o trabalho digno permitirá a identificação de variados aspectos de diferentes profissões que podem ser melhorados para que os trabalhadores percebam o próprio trabalho como digno. Muito mais pesquisa e intervenções precisam ser desenvolvidas para que se evidencie as melhores práticas de trabalho digno para as diferentes profissões em suas particularidades. Mas também, precisamos conhecer mais e melhor os trabalhos menos complexos em uma perspectiva do trabalho digno. São os empregos mais operacionais e simples aqueles que estão mais expostos à automação, à precarização e aos déficits de trabalho digno (Ryder, 2015). Tudo isso, em relação apenas ao trabalho formal. Quanto ao trabalho informal, onde as pessoas não estão protegidas pelas leis, este pode ser visto como um ambiente profícuo para práticas antiéticas e ilegais que podem e devem ser combatidas no âmbito do trabalho digno pleno para todos os trabalhadores (ILO, 2002). Da mesma forma que o nosso estudo acrescenta um pequeno contributo que nos faz compreender um pouco da realidade dos Administradores, muito ainda precisa ser feito e os Administradores também têm grande responsabilidade na promoção e defesa do trabalho digno pleno para todos.

Uma outra temática cuja literatura apenas mais recentemente começou a deixar de ser escassa, seja na Gestão e/ou na Psicologia das Organizações, são os "trabalhos que devem ser abolidos" ("work that should be abolished"). O tema muitas vezes parece passar longe das organizações pela própria escassez de estudos organizacionais. Entretanto, neste setor encontram-se o trabalho escravo, o trabalho infantil e diversas formas de exploração laboral. Apesar das dificuldades, estes são temas organizacionais que precisam ser abordados. Os Administradores atuais, como promotores do crescimento e desenvolvimento das organizações, precisam/precisarão conhecer, e atuar cada vez mais como intervenientes responsáveis na construção de organizações mais sadias e saudáveis para si, para sua comunidade e para a sociedade em geral.

De um ponto de vista geral, cada um de nós precisa se informar mais e participar mais ativamente na criação de uma cultura de trabalho digno. É uma responsabilidade comum a expansão da nossa compreensão sobre o tema e acima de tudo, é também uma responsabilidade partilhada a ação na promoção e defesa do trabalho digno para todos.

\section{Limitações e Perspectivas para o Futuro}

Dentro da área da Administração, quanto as perspectivas para o futuro, a realização de novas pesquisas pode seguir diversos caminhos, mas referimos a pelo menos dois: a partir da abordagem de uma única especialidade da Administração, ao se conhecer em maior profundidade as características do trabalho digno para esta especialidade; ou ao considerar semelhanças e diferenças no que 
se refere a outras especialidades e diferentes campos da Administração. Ambas as abordagens podem contribuir para um melhor panorama da profissão, não só no Brasil como em outros países.

Por tratar-se de uma investigação de corte transversal, não é possível inferir uma relação de causalidade entre TD, Satisfação com a vida e com o trabalho. No futuro, novas pesquisas, com uma abordagem qualitativa, bem como a coleta e análise de dados com um desenho longitudinal poderão contribuir para a compreensão em maior profundidade de potenciais flutuações do trabalho digno ao longo do tempo.

A abordagem do TD através da perspectiva POTRH considera a experiência do trabalhador em sua individualidade, sua aplicabilidade pode enriquecer o conhecimento sobre o tema e abrir novas estratégias de recursos humanos, bem como novas formas de pensar sobre as políticas e práticas nos ambientes de trabalho formal. Muito mais pesquisa ainda precisa ser desenvolvida no âmbito do trabalho informal e o mercado de trabalho como um todo (Ferraro et al., 2017). Ao considerarmos o fato de que o TD é uma das iniciativas da Agenda 2030 para o desenvolvimento sustentável (UN, 2015), espera-se que, em um futuro não muito distante, o TD seja aplicado em uma multiplicidade de contextos de trabalho, tornando-se uma ferramenta de diagnóstico para promoção de intervenções, políticas e planos de ação que objetivem a melhoria dos ambientes de trabalho em níveis local e global.

O presente estudo contribui para a compreensão das interações entre o TD e a satisfação com o trabalho e com a vida e acaba por, também, representar um retrato da dignidade e satisfação com o trabalho e com a vida percebidas pelos administradores brasileiros que atuam em sua área de formação.

\section{Referências}

Bergmann, T. J. (1981). Managers and their organizations: An interactive approach to multidimensional job satisfaction. Journal of Occupational Psychology, 54(4), 275-288. https://doi.org/10.1111/j.2044-8325.1981. tb00068.x

Beutell, N. J., \& Schneer, J. A. (2014). Job and life attitudes of managers and professionals. Journal of Psychological Issues in Organizational Culture, 4(4), 1832. https://doi.org/10.1002/jpoc. 21123

Carlotto, M. S., \& Câmara, S. G. (2008). Propriedades psicométricas do Questionário de Satisfação no Trabalho (S20/23). PsicoUSF, 13(2), 203-210. https://doi.org/10.1590/S1413-82712008000200007

Conselho Federal de Administração (2015). Perfil, formação, atuação e oportunidades de trabalho do administrador: pesquisa nacional ( $\left.6^{\mathrm{a}} \mathrm{ed}\right)$. Brasília: Conselho Federal de Administração (CFA). Recuperado de http://cfa.org.br/wp-content/ uploads/2018/02/08Pesquisa-perfil-2016 v3 web.pdf

Conselho Federal de Administração (2018). Código de Ética e Disciplina dos Profissionais de Administração. Recuperado de < http://documentos.cfa.org.br/ arquivos/resolucao 5372018 665.pdf $>$,

Conselho Federal de Psicologia (2014). Código de Ética do Conselho Federal de Psicologia (CFP). Recuperado de < http://site.cfp.org.br/wp-content/ uploads $/ 2012 / 07 / \mathrm{Co}_{0} \mathrm{CC} \% 81$ digo-de- $\% \mathrm{C} 3 \% 89$ tica.pdf $>$,

Cook, J. D., Hepworth, S. J., Wall, T. D., \& Warr, P. B. (1989). The experience of work: A compendium and review of 249 measures and their use. Suffolk: Academic Press.

Dejours, C. (2017). Prefácio. Em C. Dejours (Org.), Psicodinâmica do trabalho: Casos clínicos (pp. 5-8). Porto Alegre, RS / São Paulo, SP: Dublinense.

Diener, E. (1984). Subjective well-being. Psychological Bulletin, 95(3), 542-575. https://doi.org/10.1037/0033-2909.95.3.542

Diener, E., Emmons, R. A., Larsen, R., \& Griffin, S. (1985). The Satisfaction with Life Scale. Journal of Personality Assessment, 49, 91-95. https://doi. org/10.1207/s15327752jpa4901 13

Droussiotis, A., \& Austin, J. (2007). Job satisfaction of managers in Cyprus. EuroMed Journal of Business, 2(2). 208-222. https://doi. org $/ 10.1108 / 14502190710826068$

Ferraro, T., dos Santos, N. R., Pais, L., \& Mónico, L. (2016). Historical Landmarks of Decent Work. European Journal of Applied Business and Management, 2(1), 77-96. ISSN 2183-5594

Ferraro, T., dos Santos, N. R., Pais, L., \& Moreira, J. M. (2017). Decent Work and Work Motivation in Lawyers: an empirical research. Revista Psicologia Organizações e Trabalho, 17(4), 192-200. https://doi.org/10.17652/ $\mathrm{rpot} / 2017.4 .13908$
Ferraro, T., Pais, L., \& dos Santos, N. R. (2015). Decent work: an aim for all made by all. International Journal of Social Sciences, IV(3), 30-42. https://doi. org/10.20472/SS2015.4.2.003

Ferraro, T., Pais, L., dos Santos, N. R., \& Moreira, J. M. (2018). The Decent Work Questionnaire (DWQ): Development and validation in two samples of knowledge workers. International Labour Review, 157(2), 243-265. https://doi. $\operatorname{org} / 10.1111 /$ ilr.12039

Garcia-Izquierdo, A. L., Moscoso, S., \& Ramos-Villagrasa, P. J. (2012). Reactions to the Fairness of Promotion Methods: Procedural justice and job satisfaction. International Journal of Selection and Assessment, 20(4), 394-403. https://doi.org/10.1111/ijsa.12002

Ghiselli, R. F., La Lopa, J. M., \& Bai, B. (2001). Job Satisfaction, Life Satisfaction, and Turnover Intent: Among Food-service Managers. Cornell Hotel and Restaurant Administration Quarterly, 42(2), 28-37. https://doi. org $/ 10.1177 / 0010880401422002$

Gouveia, V. V., Milfont, T. L., Fonseca, P. N., \& Coelho, J. A., P. M. (2009). Life Satisfaction in Brazil: Testing the psychometric properties of the Satisfaction With Life Scale (SWLS) in Five Brazilian Samples. Social Indicator Research, 90, 267-277. https://doi.org/10.1007/s11205-008-9257-0

Hair, J. F., Anderson, R. E., Tatham, R. L., \& Black, W. C. (2005). Análise multivariada de dados ( $5^{\mathrm{a}}$ ed). Porto Alegre: Bookman.

Hora, G. P. R., Ribas Jr., R., \& Souza, M. A. (2018). Estado da arte das medidas em satisfação no trabalho: Uma revisão sistemática. Trends in Psychology/ Temas em Psicologia, 26(2), 971-986. https://doi.org/10.9788/TP2018.2-16Pt

International Business Machines (IBM) Corporation (2013). IBM SPSS statistics for Windows, Version 22.0. Armonk, NY: IBM Corporation.

International Business Machines (IBM) Corporation (2015). Extension bundles from IBM SPSS. USA: IBM Corporation. Retrieved from < https://www.ibm. $\mathrm{com} /$ developerworks/community/files/form/anonymous/api/library/ b5bb8a42-04d2-4503-93bb-dc45d7a145c2/document/1d445b76-d70644a6-85bf-9e3738d223a4/media/Extension $\% 20$ Commands $\% 20$ from $\% 20$ IBM $\% 20$ SPSS.pdf>

International Labour Organization. (1999). Decent work. Report of the DirectorGeneral at 87 th Session of International Labour Conference. Geneva: International Labour Office.

International Labour Organization. (2001a). Perspectives on Decent Work: Statements by the ILO Director-General. Geneva: International Labour Office.

International Labour Organization. (2001b). Reducing the Decent Work Deficit: A global challenge. Report of the Director-General at 89th Session of International Labour Conference. Geneva: International Labour Office.

International Labour Organization. (2002). Decent work and informal economy. Report VI, sixth item on the agenda, 90th Session of International Labour Conference. Geneva: International Labour Office.

International Labour Organization. (2008). Decent work: Some strategic challenges ahead. Report of the Director-General at 97th Session of International Labour Conference. Geneva: International Labour Office.

Joo, B.-K., \& Nimon, K. (2014). Two of a kind? A canonical correlational study of transformational leadership and authentic leadership. European Journal of Training and Development, 38(6), 570-587. https://doi.org/10.1108/EJTD-122013-0129

Judge, T. A., Parker, S. K., Colbert, A. E., Heller, D., \& Ilies, R. (2002). Job satisfaction: A cross-cultural review. Em N. Anderson, D. S. Ones, H. K. Sinangil, \& C. Viswesvaran (Eds.), Handbook of industrial, work and organizational psychology (Vol. 2. Organizational psychology, pp. 25-52). Thousand Oaks, California: Sage Publications.

Judge, T. A., Thoresen, C. J., Bono, J. E., \& Patton, G. K. (2001). The job satisfaction-job performance relationship: A qualitative and quantitative review. Psychological Bulletin, 127(3), 376-407. https://doi.org/10.1037/00332909.127 .3 .376

Kantak, D. M., Futrell, C. M., \& Sager, J. K. (1992). Job Satisfaction and Life Satisfaction in a Sales Force. Journal of Personal Selling \& Sales Management, 12(1), 1-7. https://doi.org/10.1080/08853134.1992.10753893

Khaleque, A., \& Choudhury, N. (1984). Job Facets and Overall Job Satisfaction of Industrial Managers. Indian Journal of Industrial Relations, 20(1), 55-64.

Kline, R. (2011). Principles and practice of structural equation modeling ( $\left.3^{\mathrm{a}} \mathrm{ed}\right) . \mathrm{NY}$ : Guilford Press.

Koh, H. C., \& Boo, E. H. Y. (2001). The link between organizational ethics and job satisfaction: A study of managers in Singapore. Journal of Business Ethics, 29(4), 309-324. https://doi.org/10.1023/A:1010741519818

Lau, C. M., Wong, K. M., \& Eggleton, I. R. C. (2008). Fairness of performance evaluation procedures and job satisfaction: the role of outcome-based and non-outcome-based effects. Accounting and Business Research, 38(2), 121-135. https://doi.org/10.1080/00014788.2008.9663325

Ling, F. Y. Y., Ning, Y., Chang, Y. H., \& Zhang, Z. (2018). Human resource management practices to improve project managers' job satisfaction. Engineering, Construction and Architectural Management, 25(5), 654-669. https:// doi.org/10.1108/ECAM-02-2017-0030

Locke, E. A. (1976). The nature and causes of job satisfaction. Em M. D. Dunnette (Ed.), Handbook of industrial and organizational psychology (pp. 12971349). Chicago: Rand McNally. 
Maroco, J. (2014). Análise de equações estruturais: Fundamentos teóricos, software \& aplicações. Portugal: Report Number.

Maroco, J., \& Garcia-Marques, T. (2006). Qual a fiabilidade do alfa de Cronbach? Questões antigas e soluções modernas? Laboratório de Psicologia, 4(1), 65-90.

Meliá, J. L., \& Peiró, J. M. (1989). La medida de la satisfacción laboral en contextos organizacionales: el Cuestionario de Satisfacción S20/23. Psicologemas, 3(5), 59-74.

Meyers, L. S., Gamst, G., \& Guarino, A. J. (2017). Applied Multivariate Research: Design and interpretation ( $\left.3^{\mathrm{a}} \mathrm{ed}\right)$. Thousand Oaks, California, USA: Sage Publications.

Ng, T. W. H., Sorensen, K. L., \& Yim, F. H. K. (2009). Does the job satisfaction - job performance relationship vary across cultures? Journal of Cross-Cultural Psychology, 40(5), 761-796. https://doi. org/10.1177/0022022109339208

Organização Internacional do Trabalho. (2009). Perfil do trabalbo decente no Brasil. Brasília: OIT

Organização Internacional do Trabalho. (2001). Perspectivas do Trabalbo Decente: Declarações de Diretor-Geral da OIT. Genebra: Secretaria Internacional do Trabalho.

Pavot, W., \& Diener, E. (2008). The Satisfaction With Life Scale and the emerging construct of life satisfaction. The Journal of Positive Psychology, 3(2), 137-152. https://doi.org/10.1080/17439760701756946

Petty, M. M., McGee, G. W., \& Cavender, J. W. (1984). A meta-analysis of the relationships between individual job satisfaction and individual performance. The Academy of Management Review, 9(4), 712-721. https://doi. org $/ 10.2307 / 258493$

Pradhan, R. K., Dash, S., \& Jena, L. K. (2019). Do HR Practices Influence Job Satisfaction? Examining the Mediating Role of Employee Engagement in Indian Public Sector Undertakings. Global Business Review, 20(1), 119-132. https://doi.org/10.1177/0972150917713895

Pituch, K. A., \& Stevens, J. P. (2016). Applied multivariate statistics for the social science: Analyses with SAS and IBM's SPSS. New York, NY: Routledge.

Qu, H., \& Zhao, X. (2012). Employees' work-family conflict moderating life and job satisfaction. Journal of Business Research, 65(1), 22-28. https://doi. org/10.1016/i.jbusres.2011.07.010

Rain, J. S., Lane, I. M., \& Steiner, D. D. (1991). A current look at the Job satisfaction/Life satisfaction relationship: Review and future considerations. Human Relations, 44(3), 287-307. https://doi. org $/ 10.1177 / 001872679104400305$

Rueda, F. J. M. (2015). Análise fatorial confirmatória da Escala de Satisfação no Trabalho nas versões de 25 e 15 itens. Revista Psicologia Organizações e Trabalho, 15(1), 82-88. https://doi.org/10.17652/rpot/2015.1.436

Ryder, G. (2015). The future of work centenary initiative. Report of the DirectorGeneral at 104th Session of International Labour Conference. Geneva: International Labour Office.

Sá, P. M. (2016). Teorias Organizacionais. Em F. Almeida (Coord.), Introdução à Gestão de Organizações (pp. 34-96). Lisboa: Escolar.

Sherry, A., \& Henson R. K. (2005). Conducting and interpreting canonical correlation analysis in personality research: A user-friendly primer. Journal of Personality Assessment, 84(1), 37-48. https://doi.org/10.1207/ s15327752ipa8401 09

Spector, P. E. (1997). Job satisfaction: Application, assessment, causes, and consequences. USA: SAGE Publications.

United Nations. (2015). Transforming our world: the 2030 Agenda for Sustainable Development. Resolution adopted by the General Assembly on 25 September 2015 (A/RES/70/1). 69th Session of UN General Assembly. New York: United Nations. Recuperado de http://www.un.org/ga/search/view doc. asp? symbol $=\mathrm{A} / \mathrm{RES} / 70 / 1$ \&Lang $=\mathrm{E}$

Vieira, V., Appio, J., \& Slongo, L. (2007). Aspects of job satisfaction in a lumber company. REGE Revista De Gestão, 14(3), 1-18. https://doi.org/10.5700/ issn.2177-8736.rege.2007.36602

Zalewska, A. M. (1999). Job satisfaction and importance of work aspects related to predominant values and reactivity. International Journal of Occupational Safety and Ergonomics, 5(4), 485-511. https://doi.org/10.1080/10803548.1999.110 $\underline{76434}$

\section{Informações sobre os autores:}

\section{Renan Lopes Cipriani}

Centro de Ciências Sociais Aplicadas, Universidade Estadual do Oeste do Paraná

Av. Felipe Wandscheer, 7157/1397

85856-850 Foz do Iguaçu, PR, Brasil

E-mail: renan_lopes@hotmail.com

\section{Tânia Ferraro}

E-mail: taniaferraro@gmail.com

\section{Cecília Leão Oderich}

E-mail: cecilia.oderich@unioeste.br 